JURNAL ILMIAH AGRINECA

ISSN : 2721-074X (Online) - 2301-6698 (Print)

Available on : http://ejournal.utp.ac.id/index.php/AFP/index

This is Under CC BY SA Licence

\title{
PERBANDINGAN PRODUKTIVITAS DAN PENDAPATAN \\ USAHATANI PADI SISTEM TANAM JAJAR LEGOWO \\ DENGAN TEGEL SERTA FAKTOR - FAKTOR YANG \\ MEMPENGARUHI PENDAPATAN
}

\section{Comparison of Productivity and Income of Rice Farming Jajar Legowo with Tegel Planting System and The Factors Influence Income}

\author{
Kaswati $^{\mathrm{a}}$, Yuliawati ${ }^{\mathrm{a}}$ \\ ${ }^{a}$ Program Studi Agribisnis, Fakultas Pertanian dan Bisnis, Universitas Kristen Satya \\ Wacana, Jl. Diponegoro 52-60, Salatiga 50711 Telp. (0298) 321212 \\ email :522013006@student.uksw.edu
}

\begin{abstract}
This study aims to determine the comparison of productivity and income of rice farming jajar legowo and tegel planting system and factors that influence income in Susukan District, Semarang Regency. The sampling method uses simple random sampling, with a total sample of this research is 69 farmers, involved 36 farmers of jajar legowo planting system and 33 farmers of tegel planting system. Data collection was carried out by interview using a questionnaire. This research uses independent sample t test and multiple linear regression. The results shows: the average productivity of paddy jajar egowo planting system was not significantly different compared to the tegel planting system. Farm income in jajar legowo planting system is bigger and significantly different from the tegel planting system. Factors that influence income are seed prices, pesticide prices, labor wages, land area, and planting systems.
\end{abstract}

Keywords: comparison of productivity, income, jajar legowo, rice farming, tegel

\begin{abstract}
ABSTRAK
Penelitian ini bertujuan untuk mengetahui perbandingan produktivitas dan pendapatan usahatani padi sistem tanam jajar legowo dengan sistem tanam tegel serta faktor-faktor yang mempengaruhi pendapatan di Kecamatan Susukan Kabupaten Semarang. Metode pengambilan sampel secara acak sederhana dengan jumlah sampel sebanyak 69 petani yang terdiri dari 36 petani sistem tanam jajar legowo dan 33 petani sistem tanam tegel. Pengambilan data dilakukan dengan wawancara menggunakan kuesioner. Analisis data dengan uji t tidak berpasangan dan regresi linier berganda. Hasil penelitian menunjukkan rata-rata produktivitas padi sistem tanam jajar legowo tidak berbeda nyata dengan sistem tanam tegel. Pendapatan usahatani pada sistem tanam jajar legowo lebih besar dan berbeda nyata dengan sistem tanam tegel. Faktor -faktor yang mempengaruhi pendapatan adalah harga benih, harga pestisida, upah tenaga kerja, luas lahan, dan sistem tanam.

Kata kunci: jajar legowo, pendapatan, perbandingan produktivitas, tegel, usahatani padi

\section{PENDAHULUAN}

Berdasarkan data Laporan Badan Ketahanan Pangan (2016) selama tahun 2016 sebagian besar petani di lokasi panel menjual gabah dalam bentuk Gabah

Kering Panen (GKP) dan Gabah Kering Giling (GKG). Harga GKP di tingkat petani berkisar antara Rp 4.057/kg - Rp $4.659 / \mathrm{kg}$. Harga tertinggi terjadi pada bulan Januari 2016, sedangkan harga terendah terjadi pada bulan April 2016. Perubahan harga GKP di tingkat petani relatif kecil, yaitu turun $0,71 \%$ dan harga
\end{abstract}


JURNAL ILMIAH AGRINECA

ISSN : 2721-074X (Online) - 2301-6698 (Print)

Available on : http://ejournal.utp.ac.id/index.php/AFP/index

This is Under CC BY SA Licence

GKP tahun 2016 cenderung stabil dengan koefisien varian sebesar $4,15 \%$. Harga GKG di tingkat penggilingan berkisar antara Rp 5.032/kg - Rp 5.548/kg. Harga tertinggi terjadi pada bulan Januari 2016 dan harga terendah pada bulan Juni 2016. Sama halnya dengan perubahan harga GKP, harga GKG di tingkat penggilingan relatif kecil, yaitu turun $0,51 \%$ dan harga GKG tahun 2016 relatif stabil dengan koefisien varian $3,01 \%$. Pada kondisi tersebut peranan pemerintah terhadap peningkatan produktivitas padi jauh lebih besar dibandingkan peranan komoditi bukan makanan (perumahan, sandang, pendidikan, dan kesehatan).

Pembangunan pertanian tanaman pangan khususnya padi tetap terfokus pada upaya peningkatan produksi yang harus diikuti dengan pengembangan usahatani berbasis agribisnis agar dapat meningkatkan pendapatan petani. Laju peningkatan produktivitas padi sawah di Indonesia cenderung melandai sehingga diindikasikan bahwa sistem intensifikasi padi sawah yang selama ini diterapkan belum mampu meningkatkan produksi dan produktivitas (Edy dkk, 2014). Peningkatan produksi tanaman pangan merupakan upaya dalam mewujutkan ketersedian pangan bagi masyarakat. Salah satu cara yang dilakukan adalah perubahan cara tanam padi sawah. Sistem tanam legowo merupakan rekayasa teknologi yang ditujukan untuk memperbaiki produktivitas usahatani padi (Hariyadi, Huda, Ali, \& Wandik, 2019).

Sistem tanam jajar legowo merupakan salah satu sistem tanam pada padi sawah yang apabila dibandingkan dengan sistem tanam lainnya memiliki keuntungan sebagai berikut: 1) Terdapat ruang terbuka yang lebih lebar diantara dua kelompok barisan tanaman yang akan memperbanyak cahaya matahari masuk ke setiap rumpun tanaman padi sehingga meningkatkan aktivitas fotosintesis yang berdampak pada peningkatan produktivitas tanaman, 2) Sistem tanaman berbaris ini memberi kemudahan petani dalam pengelolaan usahataninya seperti: pemupukan susulan, penyiangan, pelaksanaan pengendalian hama dan penyakit (penyemprotan). Disamping itu juga lebih mudah dalam mengendalikan hama tikus, 3) Meningkatkan jumlah tanaman pada kedua bagian pinggir untuk setiap set legowo, sehingga berpeluang untuk meningkatkan produktivitas tanaman akibat peningkatan populasi, 4) Sistem tanaman berbaris ini juga berpeluang bagi pengembangan sistem produksi padi-ikan (mina padi) atau parlebek (kombinasi padi, ikan, dan bebek), 5) Meningkatkan produktivitas padi hingga mencapai $10-15 \%$ (Abdulrachman, dkk., 2013).

Menurut Nila (2014) produktivitas sistem jajar legowo lebih tinggi dibandingkan produktivitas sistem tegel yaitu sebesar $3.386,7 \mathrm{~kg} / \mathrm{ha} / \mathrm{mt}$ sedangkan produktivitas sistem tegel 2.942,0 $\mathrm{kg} / \mathrm{ha} / \mathrm{mt}$. Pendapatan petani sistem jajar legowo lebih tinggi dari pada sistem tegel ditunjukkan dengan nilai Rp. 12.805.715 per hektar permusim tanam dengan $\mathrm{R} / \mathrm{C}$ sebesar 2,79 sedangkan sistem tegel sebesar Rp. 10.566.489,95 per hektar per musim tanam dengan $\mathrm{R} / \mathrm{C}$ sebesar 2,65.

Menurut penelitian Dewi (2014) jumlah output yang dihasilkan pada usahatani padi sistem tanam Jajar Legowo dan pada sistem tanam Tegel berbeda. Jumlah produksi dan produktivitas padi pada sistem tanam Jajar Legowo lebih besar dibandingkan dengan produksi dan produktivitas padi pada sistem tanam Tegel yaitu 7,03 ton/ha dan 6,99 ton/ha. Hal tersebut yang menyebabkan penerimaan usahatani padi sistem tanam Jajar Legowo lebih besar dibandingkan dengan usahatani padi sistem tanam Tegel. Peningkatan produktivitas dari sistem tanam Jajar Legowo adalah sebesar $14,06 \%$.

Dari penelitian tersebut rata - rata Sistem Tanam Jajar Legowo telah berhasil meningkatkan produktivitas dan 
This is Under CC BY SA Licence

pendapatan petani. Apakah hal yang sama terjadi di Desa Koripan Kecamatan Susukan? Apakah besar atau kecilnya produktivitas dan pendapatan petani Sistem Tanam Jajar Legowo dan Sistem Tanam Tegel dikarenakan faktor-faktor yang mempengaruhi pendapatan seperti harga benih, harga pupuk, harga pestisida, upah tenaga kerja luar keluarga dan luas lahan?

Dari rumusan masalah tersebut peneliti ingin menelusuri lebih dalam mengenai perbandingan produktivitas dan pendapatan usahatani padi beserta faktorfaktor yang mempengaruhi usahatani padi dengan Sistem Tanam JaJajar Legowo dan Sistem Tanam Tegel.

\section{METODE PENELITIAN}

Penelitian ini dilakukan di Desa Koripan Kecamatan Susukan Kabupaten Semarang. Lokasi dipilih karena sebagian besar petani di Desa tersebut mengaplikasikan sistem tanam jajar legowo dab sistem tanam tegel. Waktu penelitian dilaksanakan pada Januari 2018 - Febuari 2018.

Metode pengambilan data dengan metode survei. Pengamblan data dilakukan dengan wawancara menggunakan kuesioner. Penentuan sampel secara acak sederhana dengan jumlah sampel sebanyak 69 petani yang terdiri dari 36 petani sistem tanam jajar legowo dan 33 petani sistem tanam tegel. Analisis data dengan uji $t$ tidak berpasangan dan regresi linier berganda

Untuk mengetahui produktivitas usahatani padi di Desa Koripan digunakan rumus sebagai berikut: $\underline{(k g)}$

Produktivitas: Jumlah Produksi

\section{Luas Lahan (ha)}

Menurut Bunasor (2006) keberhasilan produksi usahatani pada akhirnya dinilai dari besarnya pendapatan (Net Return) yang diperoleh dari kegiatan usahatani. Besarnya pendapatan didapat dengan menggunakan rumus sebagai berikut:

$\pi=T R-T C$

Keterangan:

$\pi=\quad$ Pendapatan Usahatani

$\mathrm{TR}=$ Total Penerimaan

$\mathrm{TC}=$ Total Biaya

Sedangkan untuk mengetahui Pendapatan Penerimaan (TR) adalah:

$T R=Y . P y$

Keterangan :

$\mathrm{TR}=$ Total penerimaan

$\mathrm{Y}=\quad$ Produksi yang diperoleh

Py $=$ Harga $Y$

Untuk menghitung Biaya Total (TC) adalah:

$T C=F C+V C$

Keterangan :

$\mathrm{TC}=$ Total cost $/$ Biaya total

$\mathrm{TFC}=$ Fixed cost $/$ Biaya tetap

$\mathrm{TVC}=$ Variabel cost / Biaya variabel

Untuk membandingkan pendapatan usahatani padi sistem Tanam Jajar Legowo dan sistem Tanam Tegel menggunakan program Eviews 8, sebelum dianalisis harus diketahui pendapatan usahatani padi yang dihitung dengan rumus:

$$
\pi=\underset{P 4 . X 4)}{Q . P}-(P 1 . X 1+P 2 . X 2+P 3 . X 3+
$$

dimana:

$\boldsymbol{\pi}$ : pendapatan usahatani padi ( $\mathrm{Rp} / \mathrm{luas}$ lahan usahatani)

Q : jumlah/kuantitas padi dalam sekali musim tanam $(\mathrm{kg})$

$\mathrm{P}$ : harga padi $(\mathrm{Rp} / \mathrm{kg})$ 
This is Under CC BY SA Licence

$\mathrm{X} 1-\mathrm{X} 4$ : jumlah input yang digunakan

$\mathrm{P} 1$ : harga benih $(\mathrm{Rp} / \mathrm{kg})$

P2 : harga pupuk $(\mathrm{Rp} / \mathrm{kg})$

P3 : harga pestisida $(\mathrm{Rp} / \mathrm{ml})$

P4: upah tenaga kerja luar keluarga $(\mathrm{Rp} / \mathrm{HOK})$

\section{HASIL DAN PEMBAHASAN}

Tabel 1. Karakteristik Petani Sistem Tanam Jajar Legowo Dan Petani Sistem Tanam Tegel 2018

\begin{tabular}{|c|c|c|c|c|c|}
\hline \multirow{2}{*}{ No } & \multirow{2}{*}{ Uraian } & \multicolumn{2}{|c|}{ Jajar Legowo } & \multicolumn{2}{|c|}{ Tegel } \\
\hline & & n (orang) & Persentase (\%) & n (orang) & Persentase (\%) \\
\hline & Usia (tahun) & & & & \\
\hline 1. & Produktif & 35 & 97,2 & 33 & 100 \\
\hline 2. & $\begin{array}{l}\text { Non produktif } \\
\text { Pendidikan }\end{array}$ & 1 & 2,8 & 0 & 0 \\
\hline 1. & SD & 30 & 83,3 & 25 & 75,8 \\
\hline 2. & SMP & 6 & 16,7 & 6 & 18,2 \\
\hline 3. & SMA & 0 & 0 & 1 & 3,0 \\
\hline \multirow[t]{2}{*}{4.} & Perguruan Tinggi & 0 & 0 & 1 & 3,0 \\
\hline & Jenis Kelamin & & & & \\
\hline 1. & Laki - laki & 31 & 86,1 & 25 & 75,8 \\
\hline \multirow[t]{2}{*}{2.} & Perempuan & 5 & 13,9 & 8 & 24,2 \\
\hline & \multicolumn{5}{|c|}{ Jumlah Anggota Keluarga (orang) } \\
\hline 1. & $1-2$ & 12 & 33,3 & 4 & 12,1 \\
\hline 2. & $2-3$ & 4 & 11,1 & 7 & 21,2 \\
\hline 3. & $3-4$ & 11 & 30,6 & 12 & 36,4 \\
\hline 4. & $4-5$ & 8 & 22,2 & 6 & 18,2 \\
\hline 5. & $5-6$ & 0 & 0 & 4 & 12,1 \\
\hline \multirow[t]{2}{*}{6.} & \multirow{2}{*}{\multicolumn{5}{|c|}{$\begin{array}{cc}1 & 2,7 \\
\text { Status Kepemilikan Lahan }\end{array}$}} \\
\hline & & & & & \\
\hline 1. & Milik Sendiri & 26 & 72,3 & 26 & 78,80 \\
\hline \multirow[t]{2}{*}{2.} & Pemaro & 10 & 27,7 & 6 & 18,15 \\
\hline & Sewa & 0 & 0 & 1 & 3,05 \\
\hline
\end{tabular}

Sumber: Data Primer 2018

Berdasarkan Tabel 1. dengan menggunakan acuan usia produktif petani adalah 15 - 64 tahun, maka baik petani sistem tanam jajar legowo dan sistem tanam tegel berada pada usia produktif. Berdasarkan tingkat pendidikan, baik petani sistem tanam jajar legowo maupun sistem tanam tegel didominasi oleh tamatan SD. Jenis kelamin petani sistem tanam jajar legowo dan sistem tanam tegel menunjukkan laki - laki lebih banyak dibanding perempuan. Petani laki - laki merupakan tulang punggung keluarga sebagai pencari nafkah untuk memenuhi

\section{Karakteristik Responden}

Keberhasilan suatu usaha yang dilakukan petani ditentukan oleh potensi atau karakteristik yang dimiliki petani, karakteristik tersebut meliputi usia, pendidikan, jenis kelamin, jumlah anggota keluarga, dan status kepemilikan lahan, untuk jelasnya karakteristik petani di Desa Koripan dapat dilihat pada Tabel 1. 
JURNAL ILMIAH AGRINECA

ISSN : 2721-074X (Online) - 2301-6698 (Print)

Available on : http://ejournal.utp.ac.id/index.php/AFP/index

This is Under CC BY SA Licence

tanggungan maka semakin banyak juga pengeluaran petani. selain itu jumlah tanggungan keluarga juga menunjukan banyak sedikitnya tenaga kerja dalam keluarga yang dapat membantu dalam proses usahatani padi.

Status kepemilikan lahan pada petani sistem tanam jajar legowo dan sistem tanam tegel dengan status lahan milik sendiri adalah 26 orang $(72,3 \%)$ dan
26 orang $(78,8 \%)$. Hal ini menunjukan bahwa petani di Desa Koripan memiliki lahan pertanian sendiri untuk melalukan usahataninya. Petani dengan status lahan sewa sebanyak 1 orang $(3,05 \%)$ dikarenakan petani tersebut adalah pengusaha beras sekalian penebas padi sehingga petani tersebut membutuhkan lahan tambahan untuk usahataninya agar stok padi yang diolah ada berkelanjutan

Tabel 2. Rata-Rata Variabel Penelitian Sistem Tanam Jajar Legowo dan Sistem Tanam Tegel

\begin{tabular}{ccccc}
\hline No & \multicolumn{1}{c}{ Uraian } & Jajar Legowo & Tegel & Uji beda \\
\hline Harga benih $(\mathrm{Rp} / \mathrm{kg})$ & $3.616,67$ & $5.236,36$ & $0.0357^{* *}$ \\
Harga pupuk $(\mathrm{Rp} / \mathrm{kg})$ & $2.125,00$ & $2.143,18$ & 0.9669 \\
Harga pestisida $(\mathrm{Rp} / \mathrm{ml})$ & 178,29 & 156,18 & $0.0353^{* *}$ \\
Upah tenaga kerja $(\mathrm{Rp} / \mathrm{HOK})$ & $116.152,80$ & $108.048,00$ & $0.0367 * *$ \\
Luas lahan $\left(\mathrm{m}^{2}\right)$ & $2.938,47$ & $2.559,15$ & $0.0000^{* *}$ \\
\hline
\end{tabular}

Sumber: Data Primer 2018

Varietas padi yang digunakan petani di Desa Koripan petani sistem tanam Jajar Legowo maupun petani sistem tanam Tegel relatif sama yakni IR64, Ciherang, Nikongga, dan Umbul. Umumnya petani sistem tanam Jajar Legowo dan petani sistem tanam Tegel menggunakan varietas padi IR64 dengan harga berkisar $\mathrm{Rp} 3.000$ - Rp 11.000 per $\mathrm{kg}$. Berdasarkan uji beda dalam uji mann withney $u$ didapatkan nilai sebesar 0,0357 lebih kecil dari nilai probablitas 0,05 . Dapat disimpulkan bahwa Ha diterima dan Ho ditolak sehingga dapat dikaakan bahwa ada perbedaan antara harga benih padi sistem tanam Jajar Legowo dan sistem tanam Tegel.

Pupuk yang digunakan petani istem Jajar Legowo dan petani sistem tanam Tegel relatif sama yaitu pupuk kandang, Urea, Phonska, pupuk organik, dan SP-36. Umumnya petani sistem tanam Jajar Legowo dan petani sistem tanam Tegel menggunakan pupuk Urea dan Phonska. Rata - rata hara pupuk sisten tanam jajar legowo dan sistem tanam tegel adalah $\mathrm{Rp}$ $2.125,00$ per $\mathrm{kg}$ dan $\mathrm{Rp} 2.143,18$ per $\mathrm{kg}$. Berdasarkan uji beda didapatkan nilai sebesar 0,9669 lebih besar dari nilai probablitas 0,05. Dapat disimpulkan bahwa Ha ditolak dan Ho diterima sehingga dapat dikaakan bahwa tidak ada perbedaan antara harga pupuk padi sistem tanam Jajar Legowo dan sistem tanam Tegel. Hal tersebut terjdi kemungkinan pupuk yang digunakan petani yaitu pupuk yang bersubsidi oleh karena itu harga tersebut tergolong murah .

Pestisida yang digunakan petani sistem tanam Jajar Legowo dan sistem tanam Tegel yaitu Matador, Rondap, Gandasil, Furadan, Spontan, Swallo, Blass, dan Regent. Pestisida yang tidak digunakan petani sistem tanam Jajar Legowo namun digunakan petani sistem tanam Tegel yaitu Tandem, Starban, dan Akodan. Rata - rata harga pertisida pada petani sistem tanam Jajar Legowo dan petani sistem tanam Tegel yaitu Rp 178,29 per ml dan Rp 156,18 per ml. Berdasarkan uji beda didapatkan nilai sebesar 0,0353 lebih kecil dari nilai probablitas 0,05. Dapat disimpulkan bahwa Ha diterima dan Ho ditolak sehingga dapat dikaakan bahwa ada perbedaan antara harga pestisida padi sistem tanam Jajar Legowo dan sistem tanam Tegel.

Upah tenaga kerja luar keluarga di Desa Koripan yaitu terdiri dari laki - laki dan perempuan. Berdasarkan wawancara 
This is Under CC BY SA Licence

\section{Perbandingan Pendapatan}

Gambaran pendapatan usahatani padi petani sistem tanam Jajar Legowo

Tabel 4. Rata-rata penerimaan, biaya variabel dan pendapatan Petani Sistem Tanam Jajar Legowo dan Sistem Tanam Tegel

\begin{tabular}{rlcc}
\hline No & \multicolumn{1}{c}{ Uraian } & Jajar Legowo & Tegel \\
\hline 1 & Penerimaan & & \\
& - Produksi (kg) & 1290,61 & 1055,75 \\
& - Harga gabah (Rp) & 4116,66 & 4269,69 \\
2 & Biaya variabel & & \\
& - Harga benih (Rp) & 38166,66 & 58303,03 \\
& - Harga pupuk (Rp) & 278466,6 & 282115,15 \\
& - Harga pestisida (Rp) & 56433,33 & 56018,18 \\
& - Upah tenaga kerja (Rp) & 968750 & 972272,72 \\
3 & Pendapatan (Rp/ha) & 4027330,556 & 3184881,818 \\
4. & Uji beda & $0,042^{*}$ \\
\hline
\end{tabular}

Sumber: Analisis Data Primer 2018.

Pendapatan adalah seluruh penerimaan dalam bentuk rupiah setelah dikurangi biaya-biaya dalam kegiatan produksi baik langsung maupun tidak langsung terlibat dalam proses produksi. Produksi rata-rata pada petani yang menggunakan sistem tanam jajar legowo dan sistem tegel menunjukkan perbedaan yang signifikan. Hal inilah yang menyebabkan rata-rata penerimaan dan pendapatan antara petani yang menggunakan system tanam jajar legowo dan sistem tegel juga mengalami perbedaan yang signifikan. Berdasarkan Tabel 4, dapat dilihat bahwa rata-rata petani yang menanam dengan sistem jajar legowo memperoleh pendapatan sebesar $\mathrm{Rp}$ 4027330,556 per hektar per musim tanam, sedangkan rata-rata petani yang menanam dengan sistem tegel memperoleh pendapatan sebesar Rp 3184881,818 per hektar per musim tanam.

Untuk mengetahui perbedaan pendapatan petani sistem tanam jajar legowo dan sistem tanam tegel dianalisis menggunakan uji mann witney. Dari hasil uji beda mann witney terdapat hasil 0,042 , yang berarti bahwa nilai 0,042 lebih kecil dari nilai probablitas 0,05 sehingga dapat disimpulkan bahwa Ha diterima dan Ho ditolak sehingga dapat dikatakan bahwa ada perbedaan antara produktivitas padi sistem tanam Jajar Legowo dan sistem tanam Tegel. Uji beda ini membuktikan bahwa pendapatan sistem jajar dan petani sistem tanam Tegel ditampilkan pada Tabel 4. legowo lebih tinggi dari pendapatan sistem tegel, hal ini dapat dilihat dari penerimaan usahatani yang lebih besar karena produksi yang lebih tinggi.

\section{Faktor-Fakor Yang Mempengaruhi Pendapatan}

Hasil analisis diketahui faktorfaktor yang mempengaruhi pendapatan usahatani padi sisten tanam Jajar Legowo dan sistem tanam Tegel berdasarkan pada Tabel 4. 


\section{AGRINECA}

JURNAL ILMIAH AGRINECA

ISSN : 2721-074X (Online) - 2301-6698 (Print)

Available on : http://ejournal.utp.ac.id/index.php/AFP/index

This is Under CC BY SA Licence

Tabel 5. Hasil Analisis Faktor-faktor yang

Usahatani Padi Sistem Tanam Jajar Mempengaruhi Pendapatan

\begin{tabular}{lllll}
\hline \hline Variable & Coefficient & Std. Error & t-Statistic & Prob. \\
\hline \hline C & 1.133045 & 1.503040 & 0.753835 & 0.4538 \\
P1 & 0.918854 & 0.428062 & 2.146544 & $0.0357^{* *}$ \\
P2 & 0.107718 & 2.582607 & 0.041709 & 0.9669 \\
P3 & -26.89214 & 12.49332 & -2.152522 & $0.0353^{* *}$ \\
P4 & -0.041217 & 0.019305 & -2.135056 & $0.0367^{* *}$ \\
X & 1.147894 & 0.183828 & 6.244388 & $0.0000^{* *}$ \\
DUMMY & 0.991860 & 0.565215 & 1.754838 & $0.0842^{*}$ \\
\hline \hline & & & \\
R-squared & 0.461226 & Mean dependent var & 3.624420 \\
Adjusted R-squared & 0.409087 & S.D. dependent var & 2.878859 \\
S.E. of regression & 2.213005 & Akaike info criterion & 4.522506 \\
Sum squared resid & 303.6381 & Schwarz criterion & 4.749154 \\
Log likelihood & -149.0264 & Hannan-Quinn criter. & 4.612425 \\
F-statistic & 8.846017 & Durbin-Watson stat & 1.802877 \\
Prob(F-statistic) & 0.000001 & f-tabel & 2,034831 \\
\hline \hline
\end{tabular}

Sumber:Analisis Data Primer 2018.

Keterangan: $* *=$ signifikan pada $\alpha: 0,05(5 \%)$ $*$ = signifikan pada $\alpha: 0,01$ $(10 \%)$

Berdasarkan variabel Tabel 5 . diketahui bahwa nilai koefisien determinasi (adjusted $\mathrm{R}$ squared) sebesar 0,409087 atau $40,9 \%$. Hal ini berarti $40,9 \%$ variasi variabel pendapatan dijelaskan oleh variabel independen (harga benih, harga pupuk, harga pestisida, upah tenaga kerja, luas lahan dan dummy sistem tanam) sisanya $51,9 \%$ dijelaskan oleh variabel lain yang tidak ada dalam penelitian.

Uji F untuk mengetahui apakah secara bersama variabel independen mempengaruhi variabel dependen. Menurut Ghozali (2006) uji statistik F pada dasarnya menunjukkan apakah semua variabel independen yang dimasukkan ke dalam model signifikan mempengaruhi variabel dependen. Berdasarkan hasil analisis pada Tabel 4 nilai $F_{\text {hitung }}$ lebih besar dari $\mathrm{F}_{\text {tabel }}$ atau $8,846017>2,034831$ dapat disimpulkan bahwa semua variabel independen secara bersama - sama berpengaruh terhadap dependen.

Untuk melihat masing-masing pengaruh variabel independen terhadap variabel dependen $(\mathrm{Y})$ dapat dilihat dari hasil nilai probablitas statistik dengan taraf signifikansi 0,05 atau 5\%. Berdasarkan Tabel 4 dapat diketahui bahwa variabel independen yaitu harga benih (P1), harga pestisida (P3), upah tenaga kerja (P4), luas lahan (X) berpengaruh terhadap pendapatan usahatani padi pada taraf signifikansi 0,05 . Hal ini dapat dilihat dari nilai probabilitas keempat variabel independen tersebut yaitu P1 $(0,0357), \mathrm{P} 3$ $(0,0353), \mathrm{P} 4(0,0367), \mathrm{X}(0,0000)$ lebih kecil dari 0,05. Dummy sistem tanam (D) 


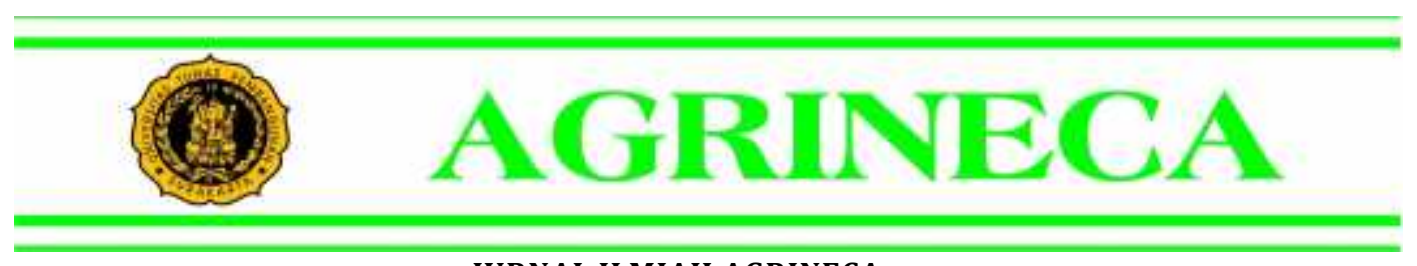

JURNAL ILMIAH AGRINECA

ISSN : 2721-074X (Online) - 2301-6698 (Print)

Available on : http://ejournal.utp.ac.id/index.php/AFP/index

This is Under CC BY SA Licence

berpengaruh terhadap pendapatan usahatani padi pada taraf signifikansi 0,01 atau $10 \%$. Hal ini dapat dilihat dari nilai probabilitas $\mathrm{D}$ $(0,0842)$ lebih besar dari 0,01 .

\begin{tabular}{|c|c|}
\hline $\begin{array}{l}\text { Persamaan } \\
\text { faktor-faktor } \\
\text { pendapatan usah } \\
\text { Jajar Legowo c } \\
\text { ditulis sebagai be }\end{array}$ & $\begin{array}{l}\text { hasil analisis regresi } \\
\text { yang mempengaruhi } \\
\text { atani padi sistem tanam } \\
\text { an sistem tanam } \\
\text { ikut: }\end{array}$ \\
\hline $\begin{aligned} \pi & \alpha+\alpha 1 \ln \\
& \ln \mathrm{P} 4+\alpha 5\end{aligned}$ & $\begin{array}{l}\alpha 2 \ln \mathrm{P} 2 \\
\mathrm{D}\end{array}$ \\
\hline pendapatan & $\begin{array}{l}1,133045+0,918854 \\
\operatorname{lnP} 1 * *+0,107718 \ln 2- \\
26,89214 \quad \ln 3^{* *} \\
0,041217 \quad \ln 4 * *+ \\
1,147894 \\
0,991860 \mathrm{D}^{*}\end{array}$ \\
\hline
\end{tabular}

Interpretasi dari persamaan yang berpengaruh terhadap pendapatan adalah sebagai berikut:

1. Koefisien regresi harga benih (P1) sebesar Rp 0,918854 per kg menunjukkan bahwa setiap kenaikan harga benih $1 \mathrm{rupiah} / \mathrm{kg}$, maka akan meningkatkan pendapatan sebesar Rp 0,918854 per $\mathrm{kg}$, dengan anggapan variabel lain (P2, P3, P4, X, dan D) konstan atau sama dengan 0 (nol). Benih yang digunakan petani dalam usahatani padi sistem tanam jajar legowo dan sistem tanam tegel rata-rata adalah jenis IR-64. Berdasarkan Tabel 2. rata rata harga benih di Desa Koripan yang digunakan petani sistem tanam Jajar Legowo adalah $\mathrm{Rp} 3.616,67 / \mathrm{kg}$ dan sistem tanam Tegel adalah Rp 5.236,36 / $\mathrm{kg}$, sebagian besar petani membeli benih dengan harga subsidi dari pemerintah yaitu 48 orang yang terdiri dari petani sistem tanam Jajar Legowo dan petani sistem tanam tegel, sehingga dapat dikatakan

2. Koefisien regresi harga pestisida (P3) sebesar-Rp 26,89214 per ml menunjukkan bahwa setiap kenaikan harga pestisida 1 rupiah/kg, maka akan terjadi penurunan pendapatan sebesar -Rp 26,89214 per ml, dengan menganggap variabel lain $(\mathrm{P} 1, \mathrm{P} 2$, $\mathrm{P} 4, \mathrm{X}$, dan D) konstan atau sama dengan 0 (nol). Pada Tabel 5 menunjukkan harga pupuk tidak berpengaruh terhadap pendapatan usahatani padi sistem tanam Jajar Legowo dan sistem tanam Tegel dengan nilai probablitas 0,9669 lebih besar dari 0,05.Berdasarkan Tabel 2 rata - rata harga pupuk di Desa Koripan yang digunakan petani sistem tanam Jajar Legowo adalah Rp $2.125 / \mathrm{kg}$ dan sistem tanam Tegel adalah Rp 2.143,182 / kg. Sebagian besar petani membeli pupuk dengan harga rata - rata yaitu 38 orang terdiri dari petani sistem tanam Jajar Legowo dan petani sistem tanam Tegel, dengan demikian walaupun harga pupuk meningkat tidak akan mempengaruhi pendapatan usahatani petani sistem tanam Jajar Legowo dan sistem tanam Tegel. Sebagian besar petani sistem tanam Jajar Legowo membeli pestisida dengan harga rata - rata tabel 2 yaitu 26 orang yang terdiri dari petani sistem tanam Jajar Legowo dan petani sistem tanam Tegel. Sedangkan 5 orang tidak menggunakan pestisida, artinya dari 69 petani hanya 64 petani yang menggunakan peestisida terdiri dari petani sistem tanam Jajar Legowo dan petani sistem tanam Tegel. Dengan demikian walaupun harga pestisida meningkat tidak akan mempengaruhi pendapatan petani sistem tanam Jajar Legowo dan petani sistem tanam Tegel.

3. Koefisien regresi upah tenaga kerja (P4) sebesar -Rp 0,041217 per HOK menunjukkan bahwa setiap kenaikan upah tenaga kerja 1 rupiah/HOK maka akan terjadi penurunan pendapatan sebesar -Rp 0,041217 per HOK dengan menganggap variabel lain $(\mathrm{P} 1, \mathrm{P} 2, \mathrm{P} 3, \mathrm{X}$, dan D) konstan atau sama dengan 0 (nol). Berdasakn Tabel 2 upah tenaga kerja rata-rata di Desa Koripan, sistem 


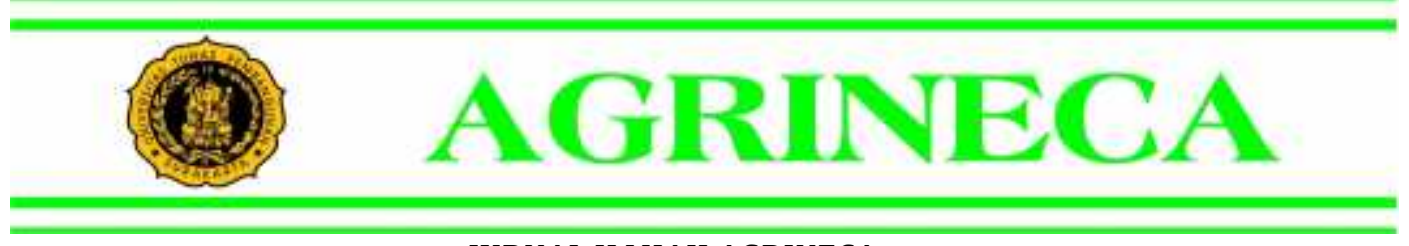

JURNAL ILMIAH AGRINECA

ISSN : 2721-074X (Online) - 2301-6698 (Print)

Available on : http://ejournal.utp.ac.id/index.php/AFP/index

This is Under CC BY SA Licence

Cahyono, L. 2010. Analisis Keuntungan Petani Padi di Kecamatan Nogosari Kabupaten Boyolali. Skripsi. Universitas Sebelas Maret. Surakarta.

Dewi, P. H. 2014. Analisis Perbandingan Pendapatan Usahatani Padi Sistem Tanam Jajar Legowo dengan Sistem Tegel Kelurahan Situmekar Sukabumi. Jurnal SEPA : Vol. 14 No.1 September $2017: 77-94$

Edyy, Yuana, Zulkarnain, Y. 2014. Analisis Produktivitas Usahatani Padi Sawah Dengan Menggunakan Traktor Tangan Dan Cara Konvensional Di Kabupaten Rejang Lebong. AGRISEP 14 No. 2 September 2014 Hal: 197 - 216| 197

Ghozali, Imam A. 2015. Analisis Multivarat dan Ekonometrika: Teori, Konsep dan Aplikasi dengan E-views 8. Semarang. Badan Penerbit UNDIP

Hariyadi, B. W., Huda, N., Ali, M., \& Wandik, E. (2019). The Effect of Tambsil Organic Fertilizer on The Growth And Results of Onion (Allium Ascalonicum L.) In Lowland. Agricultural Science, 2(2), 127138.

Kementrian Pertanian. 2017. Kedaulatan Pangan Nasional. http://www.pertanian.go.id. Diakses pada 19 Juli 2017. Pukul 12:31.

Laporan Ketahanan Pangan. 2016. Profil Kemiskinan Di Jawa Tengah 2016. http://www.bps.go.id. Diakses pada 19 juli 2017. Pukul 13:28.

Nila, S. 2014. Analisis Komparasi Produksi Dan Pendapatan Usahatani Padi Lahan Irigasi Teknis Dengan Sistem Tanam Jajar Legowo Dan Sistem Tegel Di Kabupaten Musi Rawas. SOCIETA III - $2: 69-74$, Desember 2014.

Suwarto. 2008. Produktivitas Lahan dan Biaya Usahatani Tanaman Pangan di Kabupaten Gunung Kidul. Jurnal Ekonomi Pembangunan. Vol. 9, No. 2, Desember 2008, hal. $168-183$. 